Article

\title{
Preparation of Polyvinyl Alcohol (PVA)-Based Composite Membranes Using Carboxyl-Type Boronic Acid Copolymers for Alkaline Diffusion Dialysis
}

\author{
Lizhen Peng ${ }^{\dagger}$, Xiaonan Huang ${ }^{\dagger}$, Dandan Liu, Jibin Miao *, Bin Wu ${ }^{*}$, Ming Cao, Qianqian Ge, \\ Bin Yang, Lifen Su, Ru Xia, Zhengzhi Zheng, Peng Chen and Jiasheng Qian * \\ School of Chemistry \& Chemical Engineering, Anhui University, Anhui Province Key Laboratory of \\ Environment-friendly Polymer Materials, Hefei 230601, China; xiaozahn0824@163.com (L.P.); \\ 19966505287@163.com (X.H.); 18756563397@163.com (D.L.); 13105@ahu.edu.cn (M.C.); \\ gqq@mail.ustc.edu.cn (Q.G.); yangbin@ahu.edu.cn (B.Y.); ausulf@sina.com (L.S.); xiarucn@sina.com (R.X.); \\ zzzhi@tom.com (Z.Z.); chpecp@126.com (P.C.) \\ * Correspondence: lingxiaoyu1003@163.com (J.M.); 17705@ahu.edu.cn (B.W.); qianjsh@ahu.edu.cn (J.Q.); \\ Tel.: +86-551-63861163 (J.M. \& B.W. \& J.Q.); Fax: +86-551-63861163 (J.M. \& B.W. \& J.Q.) \\ + Lizhen Peng and Xiaonan Huang contributed equally to this work.
}

Received: 28 August 2020; Accepted: 28 September 2020; Published: 14 October 2020

\begin{abstract}
Carboxyl-type boronic acid copolymers (CBACs) were synthesized by a radical polymerization method and used for the preparation of polyvinyl alcohol (PVA)-based composite membranes via a solution mixture method. The as-prepared composite membranes exhibited a water uptake $\left(\mathrm{W}_{\mathrm{R}}\right)$ of $122.6-150.0 \%$, an ion exchange capacity (IEC) of $0.0147-0.0518 \mathrm{mmol} \mathrm{g}^{-1}$, and excellent mechanical (elongation at break $\left(\mathrm{E}_{\mathrm{b}}\right.$ ) of $103.8-148.4 \%$, tensile strength (TS) of 38.7-58.6 MPa) and thermal stability. The alkali resistances of the as-prepared membranes were tested by immersing the samples into $2 \mathrm{~mol} \mathrm{~L}^{-1} \mathrm{NaOH}$ solutions at $25^{\circ} \mathrm{C}$ for $60 \mathrm{~h}$, and the results were encouraging: the mass loss and swelling degree of the as-prepared membranes were in the ranges of $1.9-5.9 \%$ and $222.6-241.9 \%$, respectively. The separation performances of the as-prepared membranes were evaluated by the diffusion dialysis (DD) process with an $\mathrm{NaOH} / \mathrm{Na}_{2} \mathrm{WO}_{4}$ mixture at room temperature. The results demonstrated that the dialysis coefficients of hydroxide $\left(\mathrm{U}_{\mathrm{OH}}\right)$ were in the range of $0.0147-0.0347 \mathrm{~m} \mathrm{~h}^{-1}$, and the separation factors (S) were in the range of 29.5-62.6. The introduced carboxyl groups from CBACs and the-OH groups from PVA were both deemed to play significant roles in the promotion of ion transport: the $-\mathrm{COO}^{-}$groups formed negatively charged transport channels for $\mathrm{Na}^{+}$by electrostatic attraction, and the $-\mathrm{OH}$ groups promoted the transport of $\mathrm{OH}^{-}$via hydrogen bonding.
\end{abstract}

Keywords: carboxyl-type boronic acid copolymers (CBACs); composite membranes; alkali recovery; diffusion dialysis (DD)

\section{Introduction}

The polymer blends are widely used in the fields of nanofiltration [1], membrane contactors [2], fuel cells [3,4], biorenewable resources [5], and capacitive deionization [6]. As a membrane separation technology that presents low energy consumption, low cost, and eco-friendliness, diffusion dialysis (DD) has exhibited broad application prospects in acid and basic wastewater treatment [7-12]. Compared with commercial applications of recovering acid via diffusion dialysis, studies of alkali recovery by diffusion dialysis are relatively limited. The key reason for this is the lack of suitable membranes, which should possess high $\mathrm{OH}^{-}$coefficients and ion selectivity, satisfactory mechanical and thermal 
stability, and excellent alkali resistance $[13,14]$. The alkali resistance of anion exchange membrane is the key to wide application.

To obtain membranes applicable for alkali diffusion dialysis, many polymer materials have been investigated, including poly (2,6-dimethyl-1,4-phenyleneoxide) (SPPO) [14,15], polyvinyl alcohol (PVA) [16-19], polyvinylidene fluoride (PVDF) [20-23], chlorosulfonated polyethylene (CSM) [24], and so on. Among these polymer matrix materials, PVA possesses good hydrophilicity and membrane-forming abilities and has drawn researchers' attentions.

For PVA-based membranes, it is necessary to introduce ion exchange groups and cross-linked structures to endow the membranes with ion exchange abilities and enhance their sustainability during operation. Therefore, many researchers have focused on this field, and certain achievements have been obtained. Liu et al. [17] mixed poly (p-styrene sulfonate) with PVA to introduce sodium sulfonate groups, and a series of cation exchange membranes (CEMs) were obtained. The as-prepared PSSNa/PVA-PSf composite membrane possessed improved water flux, efficiency of anionic dye removal, and fouling resistance to bovine serum albumin (BSA) aqueous solution. The authors considered that the improved membrane permeability and solute selectivity was due to the incorporation of PSSNa, which resulted in increased membrane pore size, surface hydrophilicity, and negative charge. Dai et al. [18] prepared PVA-based membranes by directly blending 3-mercaptopropyltriethoxysilane and benzaldehyde disulfonic acid disodium salt with PVA solution. The - $\mathrm{CHO}$ and $-\mathrm{Si}\left(\mathrm{OC}_{2} \mathrm{H}_{5}\right)_{3}$ groups can easily cross-link with -OH groups through acetal condensation and sol-gel reactions, endowing the membranes with exchangeable groups and cross-linked structures. The as-prepared membranes were applied to the DD process for alkali recovery, with the $-\mathrm{SO}_{3}{ }^{-}$and $-\mathrm{OH}$ groups anticipated to enhance $\mathrm{NaOH}$ permeability, and thus, the DD performance improved: the dialysis coefficients of $\mathrm{NaOH}\left(\mathrm{U}_{\mathrm{OH}}\right)$ in $\mathrm{NaOH} / \mathrm{NaAlO}_{2}$ solution were in the range of $2.8-23.4 \mathrm{~mm} \mathrm{~h}^{-1}$ along with the separation factors (S) ranging between 4.6 and 20.0. Wu et al. [19] prepared a kind of multiple-silicon copolymer using maleic anhydride and methacryloxypropyl trimethoxy silane as monomers, which contained a large amount of siloxane and anhydride groups. The copolymer was used to blend with PVA solution, and a series of hybrid membranes were obtained by in situ sol-gel reaction. The $\mathrm{U}_{\mathrm{OH}}$ were higher than those of conventional ion exchange membranes at both $20^{\circ} \mathrm{C}$ and $40{ }^{\circ} \mathrm{C}$ (the $\mathrm{U}_{\mathrm{OH}}$ values were in the range of $0.0095-0.0123 \mathrm{~m} / \mathrm{h}$ at $20^{\circ} \mathrm{C}$ and $0.0155-0.0208 \mathrm{~m} / \mathrm{h}$ at $40{ }^{\circ} \mathrm{C}$ ). The double $-\mathrm{COOH}$ structure was considered to play important roles during ion transport. A green method for the preparation of PVA-based cation exchange hybrid membranes has been introduced by Hao et al. [25] through the use of 3-trihydroxysilyl-1-propanesulfonic acid (THOPS). THOPS contains both cation exchange groups $\left(-\mathrm{SO}_{3} \mathrm{H}\right)$ and $\mathrm{Si}(\mathrm{OH})_{3}$ groups, which can directly cross-link with PVA by the condensation reaction between $\mathrm{Si}-\mathrm{OH}$ and $\mathrm{PVA}-\mathrm{OH}$ groups. The obtained membranes exhibited potential application in alkaline diffusion dialysis, with $\mathrm{U}_{\mathrm{OH}}$ values in the range of $0.011-0.022 \mathrm{~m} \mathrm{~h}^{-1}$ and $S$ values in the range of 11.6-20.6.

In our previous work, Liu et al. [26] prepared sulfonic acid-type boronic acid copolymers (BACs) and confirmed the potential application of BACs in the preparation of PVA-based composite membranes for alkaline diffusion dialysis. The as-prepared membranes exhibited encouraging separation performance, with optimal $\mathrm{OH}^{-}$dialysis coefficient $\left(\mathrm{U}_{\mathrm{OH}}\right)$ and separation factor $(\mathrm{S})$ values of $0.0079-0.0150 \mathrm{~m} \mathrm{~h}^{-1}$ and 53.2, respectively. To extend the application of BACs and determine the relationship between BACs and the separation performance of composite membranes, we synthesized a novel kind of carboxyl-type BAC and introduced it to prepare PVA-based composite membranes. The monomer ratio of BACs was evaluated by the results of the diffusion dialysis test, and the as-prepared membranes exhibited relatively higher $\mathrm{U}_{\mathrm{OH}}$ and $\mathrm{S}$ values than those of a previous report, which would be due to the similar molecular chain structures and good compatibility between the PVA and the carboxyl-type BACs. The alkaline resistance of the membranes has been effectively improved. 


\section{Materials and Methods}

\subsection{Materials}

PVA (purity greater than 99\%), ammonium persulphate $\left(\left(\mathrm{NH}_{4}\right)_{2} \mathrm{~S}_{2} \mathrm{O}_{8}\right)$, sodium acrylate (SA), sodium hydrogen sulfite $\left(\mathrm{NaHSO}_{3}\right), \mathrm{Na}_{2} \mathrm{WO}_{4}, \mathrm{NaOH}$, and $\mathrm{HCl}$ of analytical purity were purchased from Sinopharm Chemical Reagent Co., Ltd. (Shanghai, China). Additionally, 3-acrylamido phenylboronic acid (AAPBA) of analytical purity was purchased from Boron Nobel Technology Co., Ltd. (Beijing, China). A 5\% solution of PVA was formed by dissolving the polymer into deionized water as described in previous work [24]. The mixture of $\mathrm{NaOH}(1.0 \mathrm{~mol} \mathrm{~L}-1) / \mathrm{Na}_{2} \mathrm{WO}_{4}\left(0.10 \mathrm{~mol} \mathrm{~L}^{-1}\right)$ was prepared fresh [13], and deionized water was used during the experiment.

\subsection{Synthesis of Boronic Acid Copolymers}

Similar with our previous work [26], the typical synthesis process of BACs was as follows: $0.94 \mathrm{~g}$ SA and $0.191 \mathrm{~g}$ AAPBA were dissolved in $60 \mathrm{~mL}$ deionized water and stirred by magnetic force to form a transparent solution. At this time, the $\mathrm{pH}$ value was measured as 7. Then, $15.2 \mathrm{~mL} \mathrm{NaOH}$ $\left(1 \mathrm{~g} \mathrm{~L}^{-1}\right)$ was added to the solution above at stirring until the solution $\mathrm{pH}$ was adjusted to 8 . Next, a mixture of $4.5 \mathrm{mg}$ of SHS and $13.6 \mathrm{mg}$ of APS was added into the above-mentioned solution under continuous stirring at room temperature. The transparent solution was heated to $45^{\circ} \mathrm{C}$ and maintained for $12 \mathrm{~h}$ under vigorous stirring. Finally, an aqueous solution of BACs was obtained, and the BAC was partly precipitated and washed with ethanol several times. The obtained BACs were stored in glass desiccators for characterization, and the reaction process was displayed in Scheme 1.

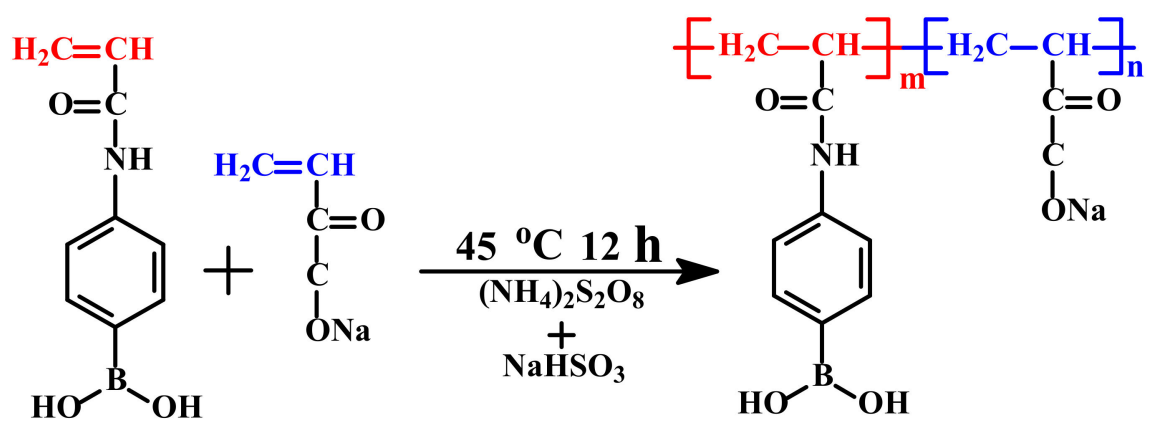

Scheme 1. Synthesis process of boronic acid copolymers (BACs).

\subsection{Preparation of PVA-Based Composite Cationic Membranes}

The obtained BACs aqueous solution was blended with $40 \mathrm{~mL}$ of $5 \%$ PVA solution under vigorous stirring with various mass ratios (BACs to PVA): $0 \%, 0.5 \%, 1 \%, 2 \%$, and $4 \%$. The pH of the mixture was maintained at 8-9, and the reaction time was $30 \mathrm{~min}$ at $25^{\circ} \mathrm{C}$. The obtained solutions were cast onto a clean glass plate $(20 \mathrm{~cm} \times 20 \mathrm{~cm})$ and dried in air at $25^{\circ} \mathrm{C}$. The as-prepared membranes were peeled off and heated from 60 to $100{ }^{\circ} \mathrm{C}$ with a heating rate of $10^{\circ} \mathrm{C} \mathrm{h}^{-1}$ after the solvent had evaporated completely. These treatment conditions were in accordance with our previous work [25], and the as-prepared membranes were marked as $0 \%, 0.5 \%, 1 \%, 2 \%$, and $4 \%$, based on the mass ratio of BAC to PVA. The viscosity of the casting solution increased obviously when the dosage of BACs reached $6 \%$ and it is difficult to form a membrane; therefore, the upper limit dosage of BACs was set at $4 \%$.

\subsection{Characterizations and Diffusion Dialysis (DD) Testing}

The Fourier transform infrared spectroscopy (FTIR) of BACs was obtained on a Nicolet iS10 spectrometer and the scanning range was set from $400 \mathrm{~cm}^{-1}$ to $4000 \mathrm{~cm}^{-1}$. The ${ }^{1} \mathrm{H}-\mathrm{NMR}$ spectrum of BACs was obtained by a Bruker NMR spectrometer (Advance II $400 \mathrm{MHz}$, Bruker, Germany). The thermal stabilities of the as-prepared membranes were tested by a Shimadzu TGA-50H analyzer 
(Tokyo, Japan) under a nitrogen atmosphere at a heating rate of $10^{\circ} \mathrm{C} \mathrm{min}^{-1}$ from room temperature to $800{ }^{\circ} \mathrm{C}$. The mechanical properties of the as-prepared membranes were measured by a microcomputer control electronic universal testing machine (Instron 5967, Instron (Shanghai) Test Equipment Trading Co., Ltd., Shanghai, China) at $25^{\circ} \mathrm{C}$, and the samples were cut into a dumbbell shape before testing. The tensile rate was set at $25 \mathrm{~mm} \mathrm{~min}^{-1}$, and the initial gauge length was $25 \mathrm{~mm}$. The microstructure of the membranes was observed by microscopic scanning electron microscopy (S-4800, Hitachi Company, Tokyo, Japan) after gold coating treatment. The water uptake $\left(\mathrm{W}_{\mathrm{R}}\right)$, ion exchange capacities (IECs), and alkali resistance of the membrane samples were tested by the methods that have been described in our previous works, and two parallel samples were tested synchronously $[27,28]$.

In a typical DD test, the membrane samples were first immersed in the $\mathrm{NaOH} / \mathrm{Na}_{2} \mathrm{WO}_{4}$ mixture for $2 \mathrm{~h}$ and then fixed between two separated compartments. The $\mathrm{NaOH} / \mathrm{Na}_{2} \mathrm{WO}_{4}$ mixture and deionized water were placed into the two compartments. The effective areas were $6 \mathrm{~cm}^{2}$, and the liquid volume in each compartment was $100 \mathrm{~mL}$. Both solutions in each compartment were stirred at the same rate to reduce the influence of concentration polarization. The testing time was controlled at $1 \mathrm{~h}$, which was in line with our previous work $[15,29]$. Next, the mixture and the diffusate were removed from both sides. The concentration of $\mathrm{OH}^{-}$was determined by the $\mathrm{HCl}$ titration method, while the concentration of $\mathrm{WO}_{4}{ }^{2-}$ was measured by thiocyanate spectrophotometry [30]. The separation factor (S) was the ratio of the dialysis coefficient $(U)$ of $\mathrm{OH}^{-}$and $\mathrm{WO}_{4}{ }^{2-}$. The dialysis coefficient could be calculated by the following formula:

$$
U=\frac{M}{A t \Delta C}
$$

where $M$ is the molar amount of material transfer $(\mathrm{mol}), A$ is the effective area $\left(\mathrm{m}^{2}\right), t$ is the experimental time (h), and $\Delta C$ is the average logarithm of the concentration of two compartments $\left(\mathrm{mol} \mathrm{m}^{-3}\right)$. The calculated formula was as follows:

$$
\Delta C=\frac{C_{f}^{0}-\left(C_{f}^{t}-C_{d}^{t}\right)}{\ln \left[C_{f}^{0} /\left(C_{f}^{t}-C_{d}^{t}\right)\right]}
$$

where $C_{f}^{0}$ and $C_{f}^{t}$ are the ion concentrations of the diffusate at time 0 and $t$, respectively, while $C_{d}^{t}$ is the ion concentration of the feed solution at time $t$.

\section{Results}

\subsection{Structure Characterization of $B A C s$}

FTIR and ${ }^{1} \mathrm{H}-\mathrm{NMR}$ analyses were performed to confirm the structure of the synthesized BACs, and the results are shown in Figures 1 and 2, respectively. The FTIR spectra of the BACs and monomers are shown in Figure 1. The tensile vibration absorption peak of $C=C$ at $1640 \mathrm{~cm}^{-1}$ disappeared in the FTIR spectrum of BACs, confirming the successful polymerization between AAPBA and SA. The broad peak in the range of $3200-3600 \mathrm{~cm}^{-1}$ corresponded to the stretching vibrations of $-\mathrm{OH}$ groups, which indicated that the polymer contained a large amount of hydroxyl groups. The tensile vibration absorption peak of $\mathrm{COO}^{-}$at $1363 \mathrm{~cm}^{-1}$ indicated that the carboxyl group was successfully bonded to AAPBA.

The ${ }^{1} \mathrm{HNMR}$ spectrum of the as-synthesized BACs in $\mathrm{D}_{2} \mathrm{O}$ was shown in Figure 2. It could be observed from the figure that $\delta=3.6 \mathrm{ppm}$ and $1.1 \mathrm{ppm}$ were the methylene and methyl peaks of the solvent ethanol, respectively. As the ${ }^{1} \mathrm{HNMR}$ of the polymer was not as clear as the monomer, some peaks were attributed mainly to the position of the peaks. The broad peak at $\delta=6.5-8.0 \mathrm{ppm}$ was attributed to protons on the benzene ring, and the strong peak at $4.8 \mathrm{ppm}$ was from the solvent hydrazine. The proton chemical shift of $-\mathrm{CH}=\mathrm{CH}_{2}$ in the monomer was 5-6 ppm, and this signal was absent in the polymer, with concomitant growth of signals at 1.2-3.0 ppm, which suggests that the vinyl protons disappear in the polymer. The proton chemical shifts of $-\mathrm{CH}$ and $-\mathrm{CH}_{2}$ overlap 
each other, and the tensile vibration peak corresponding to $C=C$ in the infrared spectrum disappeared. Based on the above results, we conclude that BACs were successfully synthesized.

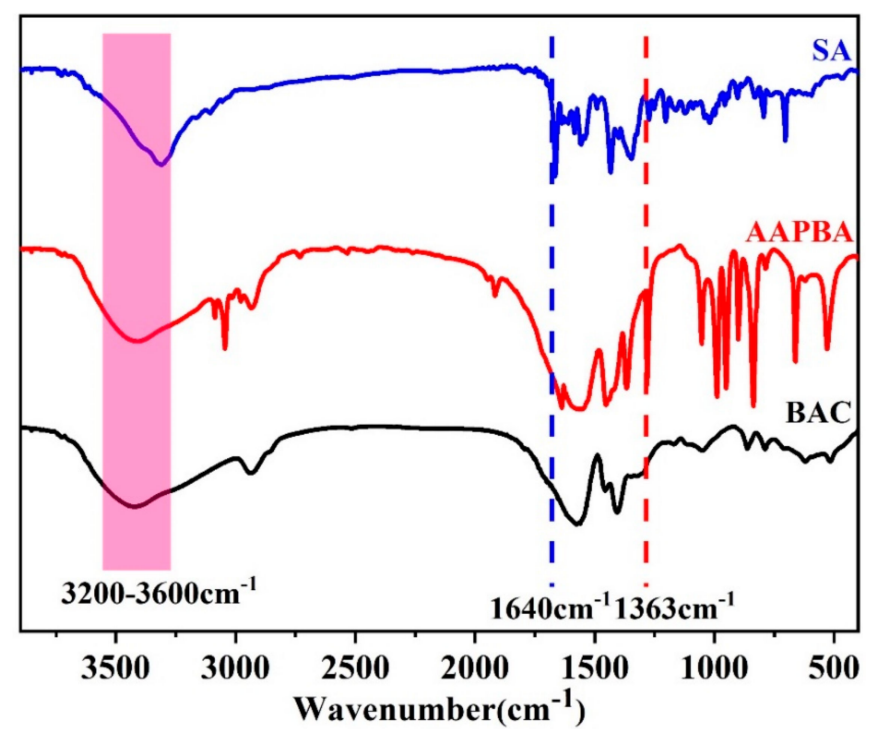

Figure 1. Fourier transform infrared spectroscopy (FTIR) of the BACs and monomers.

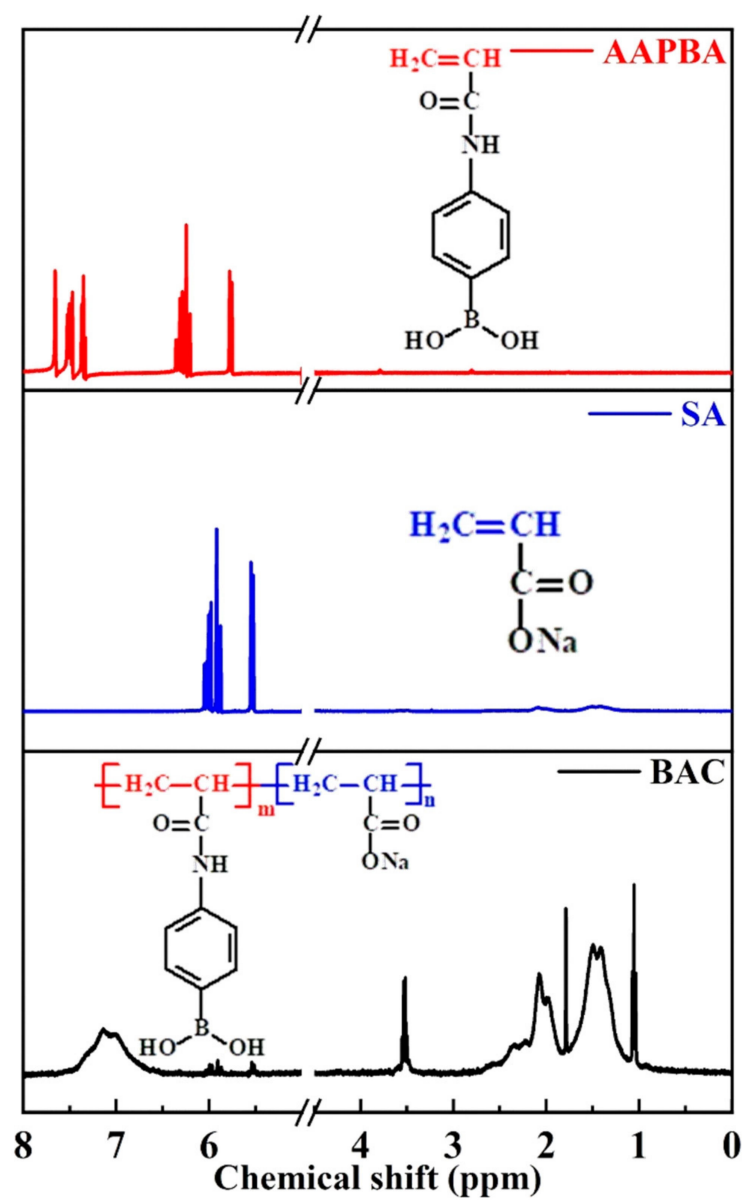

Figure 2. ${ }^{1} \mathrm{H}-\mathrm{NMR}$ spectrum of the 3-acrylamido phenylboronic acid (AAPBA), sodium acrylate (SA) and $\mathrm{BACs}$ in $\mathrm{D}_{2} \mathrm{O}$. 


\subsection{IECs and $W_{R}$ of As-Prepared Membranes}

The $W_{R}$ and IEC results of the as-prepared membranes are shown in Table 1 . The $W_{R}$ values were in the range of $122.6-150.0 \%$ and all the composite membranes exhibited higher hydrophilicity than that of the blank membrane sample, which indicated that the involvement of BACs promoted the adsorption of water. This outcome could be explained regarding two aspects: First, the $-\mathrm{COO}^{-}$groups possessed higher hydrophilicity than $-\mathrm{OH}$ groups [27], and thus, the $\mathrm{W}_{\mathrm{R}}$ of composite membranes increased with increasing BACs dosage; and second, the cross-linked reaction between the - $\mathrm{OH}$ and $-\mathrm{B}(\mathrm{OH})_{2}$ groups could increase the density of the composite membranes, which would prevent the membranes from adsorbing water molecules. Therefore, the $W_{R}$ of the as-prepared membranes first markedly increased and then slightly decreased as the dosage of BACs increased to $4 \%$. The $W_{R}$ of the composite membranes was in a moderate range compared with that observed in previous research [26], making it suitable for alkaline DD.

Table 1. IECs, $W_{R}$, and thickness of the as-prepared membranes.

\begin{tabular}{cccc}
\hline BAC Dosage & $\mathbf{W}_{\mathbf{R}} \mathbf{( \% )}$ & IEC $(\mathbf{m m o l} / \mathbf{g})$ & Thickness $(\boldsymbol{\mu m})$ \\
\hline $0 \%$ & $92.2 \pm 1.2$ & $/$ & $51 \pm 2$ \\
$0.5 \%$ & $122.7 \pm 0.9$ & 0.015 & $77 \pm 1$ \\
$1 \%$ & $129.7 \pm 0.9$ & 0.026 & $86 \pm 1$ \\
$2 \%$ & $150.0 \pm 0.8$ & 0.038 & $73 \pm 2$ \\
$4 \%$ & $137.5 \pm 0.7$ & 0.052 & $85 \pm 1$ \\
\hline
\end{tabular}

The IECs of the as-prepared membranes are shown in Table 1. Compared with those in previous reports $[15,26,28,29]$, the IECs of the membranes in this work were relatively lower. As the IECs of the as-prepared membranes were mainly derived from the number of $-\mathrm{COO}^{-}$groups, the IEC values increased gradually from 0.015 to $0.052 \mathrm{mmol} \mathrm{g}^{-1}$ with increasing BACs dosage. This result also confirmed the successful cross-linking reactions between PVA and BACs. Table 2 sums up the IEC, $\mathrm{U}_{\mathrm{OH}}$, and $\mathrm{S}$ values reported in previous studies on membranes. It can be seen from the data that the higher $\mathrm{U}_{\mathrm{OH}}$ and $\mathrm{S}$ values were obtained at lower IEC in our work. Therefore, the membrane structure plays an important role in membrane performance.

Table 2. IEC, $\mathrm{U}_{\mathrm{OH}}$, and separation factors (S) of membranes in previous literatures.

\begin{tabular}{ccccc}
\hline Membranes & IEC $/ \mathbf{m m o l ~} \mathbf{~ g}^{-\mathbf{1}}$ & $\mathbf{U}_{\mathbf{O H}} / \mathbf{m ~ h}^{-\mathbf{1}}$ & $\mathbf{S}$ & References \\
\hline PVA-P(AA-co- $\gamma$-MPS) & $0.76-0.9$ & $0.01-0.042$ & $25.5-95.7$ & {$[10]$} \\
PVA-BADSANa-MPTES & $0.98-1.36$ & $0.0028-0.0234$ & $4.6-20.0$ & {$[18]$} \\
PVA-P(AA-co- $\gamma$-MPS) & $1.39-1.78$ & $0.0095-0.0123$ & $28.4-54.4$ & {$[19]$} \\
PVA-P(THOPS-Na) & $0.7-1.56$ & $0.011-0.022$ & $11.6-20.6$ & {$[25]$} \\
PVA-P(AAPBA-AMPS) & $0.79-1.17$ & $0.008-0.015$ & $15-55$ & {$[26]$} \\
PVA-P(SAS-Co-VTMS) & $0.14-0.45$ & $0.0065-0.0086$ & $24.4-51.6$ & {$[27]$} \\
PVA/SPPO/SiO & $0.44-1.34$ & $0.007-0.013$ & $12.5-181$ & {$[30]$} \\
PVA-(MS-HPW) & $0.015-0.03$ & $0.00767-0.0115$ & $21.5-88.8$ & {$[31]$} \\
PVA-BAC & $0.0147-0.0518$ & $0.0147-0.0347$ & $29.5-62.6$ & This Work \\
\hline
\end{tabular}

\subsection{Alkali Resistance Testing Results of As-Prepared Membranes}

The alkali resistance of the as-prepared membranes was represented by the swelling degree and mass loss results, which are shown in Figure 3. The composite membranes exhibited a lower swelling degree and mass loss than those of the pure PVA membrane, which indicated that the incorporation of BACs into the PVA matrix was advantageous for promoting the alkali resistance of the composite membranes. The swelling degrees of composite membranes were in the range of $222-250 \%$ and tended to decrease first and then slightly increase as the dosage of BACs increased to $4 \%$. The reasons might be as follows: the swelling resistance of the composite membranes was enhanced compared with that of 
pure PVA when the dosage of BACs was less than $4 \%$, which was mainly due to the increased density as the dosage of BACs increased. When the dosage of BACs was $4 \%$, the slightly increased tendency of the swelling degree was mainly due to the increased content of the $-\mathrm{COO}^{-}$groups, which were more hydrophilic than the $-\mathrm{OH}$ groups.

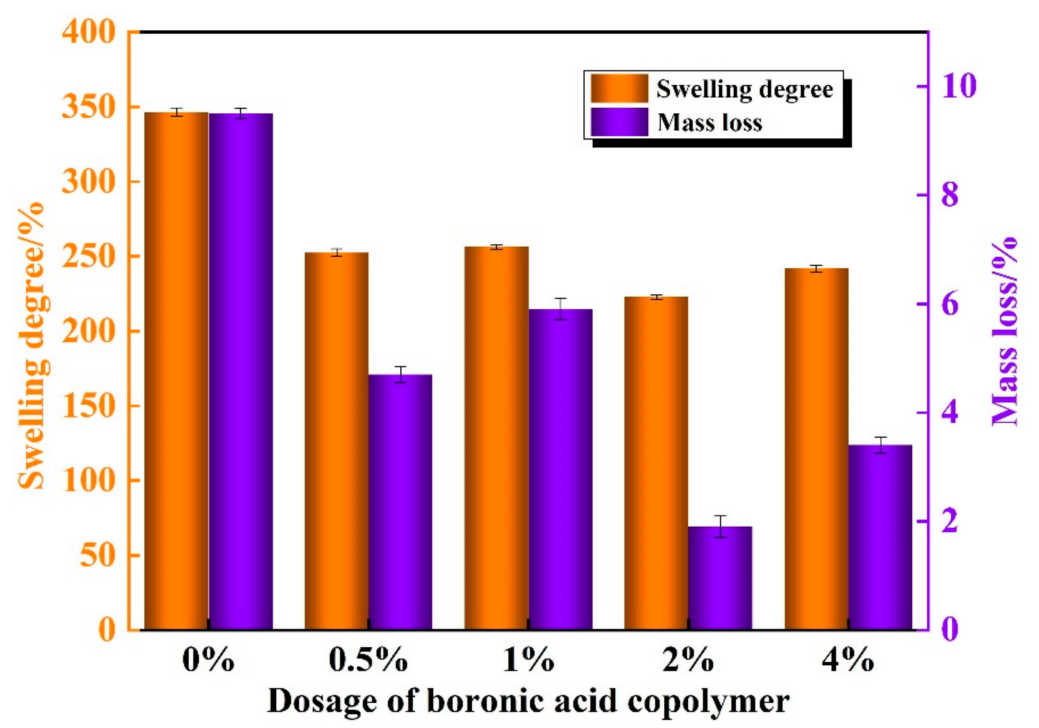

Figure 3. Alkali resistance testing results of as-prepared membranes.

The mass loss of the composite membranes was in the range of 1.9-5.9\%, which was far lower than that of the pure PVA membrane (9.7\%). Considering that the weight loss of the composite membranes was primarily due to the dissolution of dissociated PVA chains, the results revealed that the cross-linked structure between the $-\mathrm{OH}$ and $-\mathrm{B}(\mathrm{OH})_{2}$ groups increased the density of the composite membranes and prevented the attack of $\mathrm{OH}^{-}$on the PVA matrix. The composite membranes exhibited excellent alkali resistance at room temperature and were suitable for alkaline diffusion dialysis application [31,32]. The composite membranes showed optimal alkali resistance when the dosage of BACs was $2 \%$, with a swelling degree of $222.6 \%$ and a mass loss of $1.9 \%$.

\subsection{Mechanical Properties of As-Prepared Membranes}

The mechanical properties of the as-prepared membranes, including tensile strength (TS) and elongation at break $\left(E_{b}\right)$, are shown in Table 3 . The TS and $E_{b}$ of the as-prepared membranes were in the range of $38.7-58.6 \mathrm{MPa}$ and $103.8-148.4 \%$, respectively. Compared with that of the blank sample, the TS values of the composite membranes indicated trends of first decreasing and then increasing. The cross-linking reaction between $-\mathrm{B}(\mathrm{OH})_{2}$ groups from $\mathrm{BAC}$ and the hydroxyl groups of the PVA main chain could cause rearrangement of the PVA chains, which destroyed the ordered arrangement of the original polymer chains and resulted in a decrease in the strength and flexibility of the composite membranes. As the dosage of BACs increased, the number of cross-linking points between PVA and BACs increased, and the molecular chains became less prone to moving. Thus, the TS values of the membranes increased markedly. The $\mathrm{E}_{\mathrm{b}}$ values of the as-prepared membranes were significantly reduced when the number of BACs was less than $4 \%$, which was due to the restricted motion of the PVA chains with increasing cross-linking degree. When the dosage of BACs increased to $4 \%$, the obvious increase in the $\mathrm{E}_{\mathrm{b}}$ value was attributed to the increasing number of tangling points between the PVA and BACs, as well as the number of hydrogen bonds between the $-\mathrm{B}(\mathrm{OH})$ groups of PVA [29]. 
Table 3. Mechanical properties of the as-prepared membranes.

\begin{tabular}{ccc}
\hline BACs Dosage & TS $(\mathbf{M P a})$ & $\mathbf{E}_{\mathbf{b}} \mathbf{( \% )}$ \\
\hline $0 \%$ & $45.1 \pm 2.4$ & $131.3 \pm 6.9$ \\
$0.5 \%$ & $38.7 \pm 2.0$ & $103.8 \pm 3.0$ \\
$1 \%$ & $42.2 \pm 2.6$ & $108.1 \pm 7.3$ \\
$2 \%$ & $58.6 \pm 2.4$ & $112.2 \pm 3.6$ \\
$4 \%$ & $52.6 \pm 2.3$ & $148.4 \pm 2.9$ \\
\hline
\end{tabular}

\subsection{Thermal Stability Properties of As-Prepared Membranes}

The thermogravimetric (TG) and differential thermogravimetric (DTG) curves of the as-prepared membranes are shown in Figure 4 and Table 4, from which three mass loss peaks of the composite samples could be observed. The first peak before $200^{\circ} \mathrm{C}$ corresponded to the loss of adsorbed water. The second peak in the range of $200-30{ }^{\circ} \mathrm{C}$ corresponded to the decomposing of $\mathrm{OH}^{-}$and $-\mathrm{COO}^{-}$ groups [27], from which a complicated tendency could be observed, which was due to the forming of a cross-linked interaction between $-\mathrm{OH}$ and $-\mathrm{B}(\mathrm{OH})_{2}$ groups. The results showed that increasing amounts of BAC had little effect on the thermal stability of the functional groups. The $\mathrm{OH}^{-}$and $-\mathrm{COO}^{-}$groups tended to degrade easily due to the rearrangement of the PVA molecular chains. The third weight loss peak between 400 and $500{ }^{\circ} \mathrm{C}$ corresponded to the decomposing of the PVA backbone. The residual mass of the composite membranes was obviously higher than that of pure PVA, which indicated that the enhanced entanglement between the PVA molecules and BAC was also advantageous for the thermal stability of the membrane backbones. In short, the presence of BACs exhibited slight effects on the thermal stability of the $\mathrm{OH}^{-}$and $-\mathrm{COO}^{-}$groups, while the stability of the carbon chains was obviously promoted.
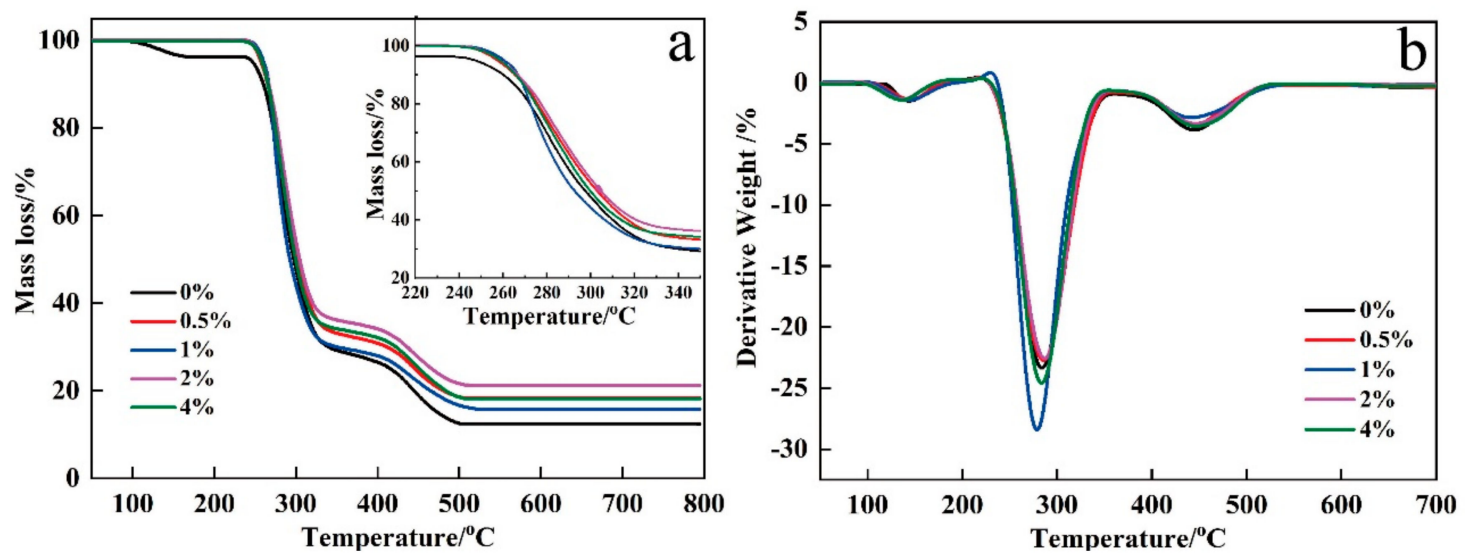

Figure 4. Thermogravimetric (TG) (a) and differential thermogravimetric (DTG) (b) curves of the as-prepared membranes.

Table 4. IDT a and Td b values of the as-prepared membranes.

\begin{tabular}{cccccc}
\hline Dosage of Boronic Acid Copolymer & $\mathbf{0 \%}$ & $\mathbf{0 . 5} \%$ & $\mathbf{1 \%}$ & $\mathbf{2 \%}$ & $\mathbf{4 \%}$ \\
\hline $\operatorname{IDT}^{\mathrm{a}}\left({ }^{\circ} \mathrm{C}\right)$ & 209 & 219 & 220 & 238 & 229 \\
$\operatorname{Td}^{\mathrm{b}}\left({ }^{\circ} \mathrm{C}\right)$ & 247 & 257 & 260 & 259 & 258 \\
\hline
\end{tabular}

a IDT is the initial decomposition temperature determined from thermo gravimetric analysis (TGA) thermograms.

$\mathrm{b}$ Thermal degradation temperature (Td) is defined as the temperature at which the weight loss is $5 \%$ in the

TGA thermograms.

\subsection{Microstructures of As-Prepared Membranes}

The cross-section $(a-e)$ and surface $\left(a^{\prime}-e^{\prime}\right)$ SEM images of the as-prepared membrane with different mass ratios of BACs are exhibited in Figure 5. With the increase of graphene content, due to its good 
compatibility, no obvious phase separation was observed on the surface. However, when the mass fraction reached $4 \%$, phase separation appeared on the cross section. We tried to increase the dosage of BACs (e.g., 6\%), but there was high viscosity resulting in the heterogeneity of the nanocomposites; the solution cannot form a membrane. These membranes exhibited smooth, uniform and dense cross-sectional structures when the dosage of BACs was less than $4 \%$. The results confirmed the compatibility between the PVA matrix and BACs, which was due to the forming of hydrogen bonds between the $-\mathrm{OH}$ and $-\mathrm{B}(\mathrm{OH})_{2}$ groups, as well as the structural comparability between PVA and BACs. However, the composite membrane revealed obvious phase separation when the dosage of BACs was $4 \%$. The results indicated that excessive dosage of BACs had an obvious effect on the microscopic structure of the composite membranes, and thus, the membrane formation process became more difficult. Considering the microstructure of the as-prepared membranes, the dosage of BACs should be controlled to less than $4 \%$, and then, composite membranes with dense, uniform microstructures can be obtained.
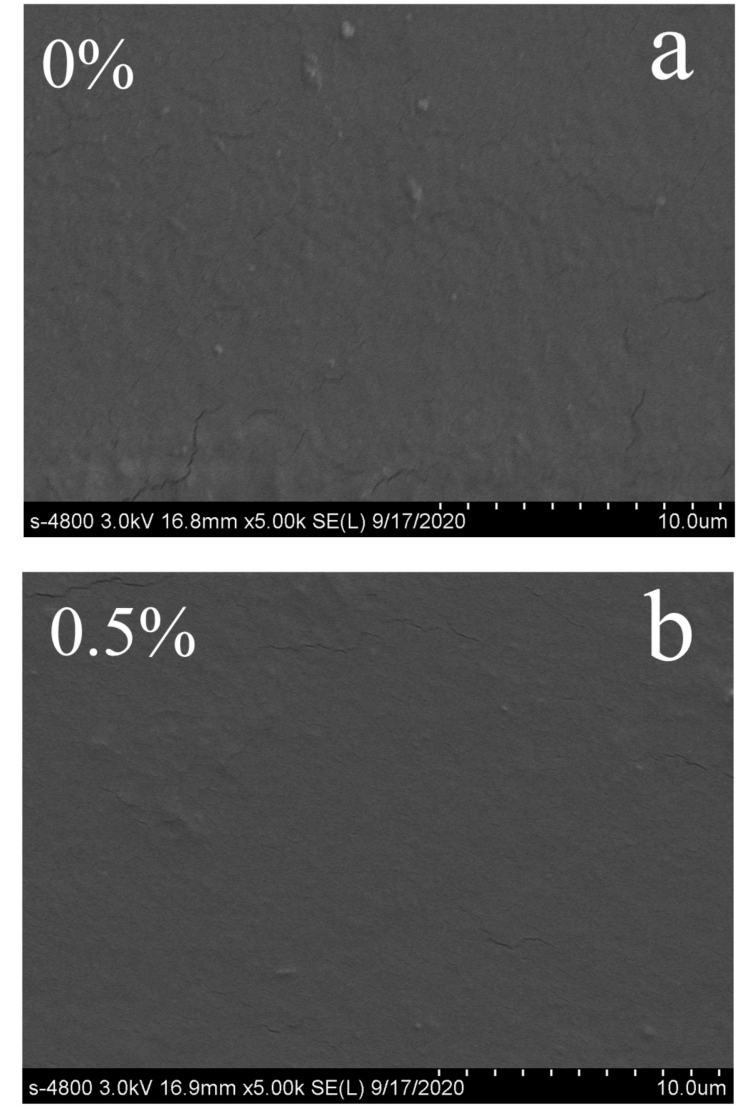
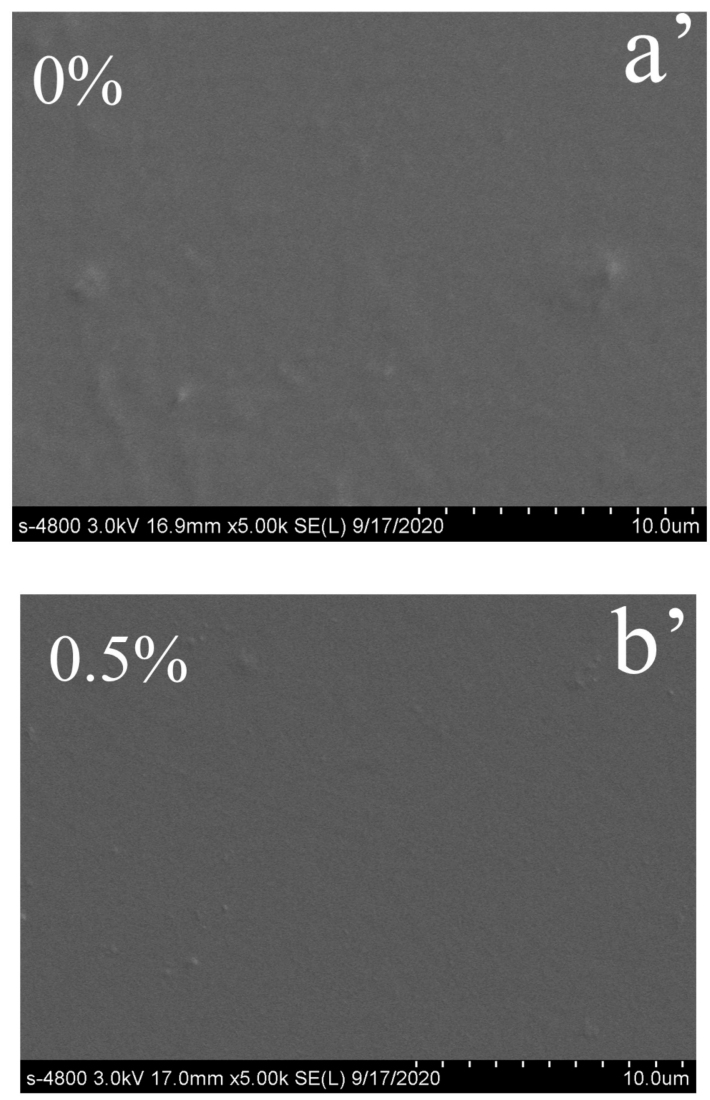

Figure 5. Cont. 

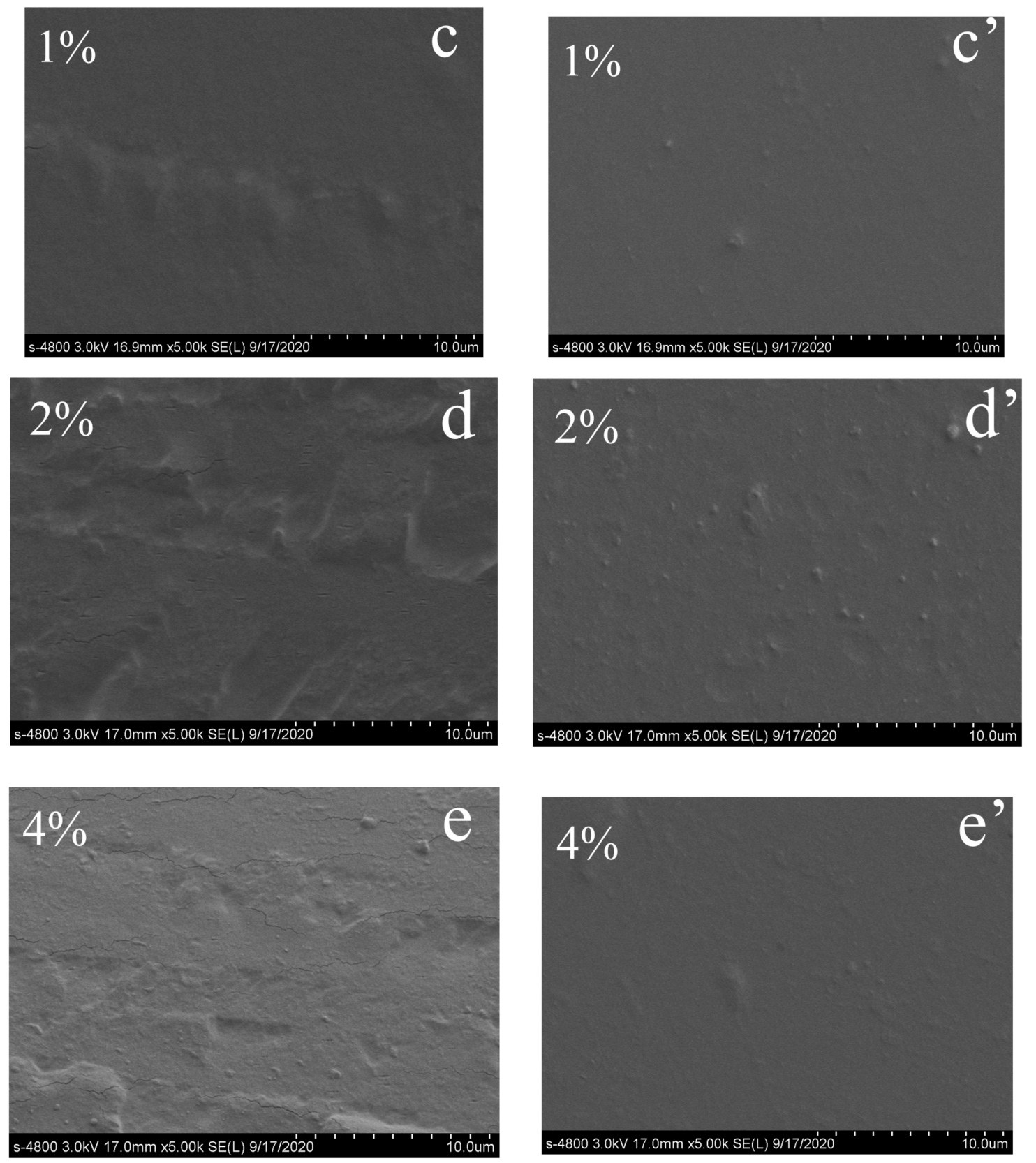

Figure 5. Cross-sectional (a-e) and surfaces ( $\left.\mathbf{a}^{\prime}-\mathbf{e}^{\prime}\right)$ scanning electron microscopy (SEM) images of the as-prepared membranes with different mass ratios of BACs.

\subsection{Results of the DD Test}

The dialysis coefficients of $\mathrm{OH}^{-}\left(\mathrm{U}_{\mathrm{OH}}\right)$ and the separation factors (S) of the as-prepared membranes are shown in Figure 6. The $\mathrm{U}_{\mathrm{OH}}$ of the membranes was in the range of 0.0147 to $0.0347 \mathrm{~m} \mathrm{~h}^{-1}$, which was higher than that in most existing studies $[18,25,31]$. The results indicated that the presence of BACs in the PVA was advantageous to the enhancement of $\mathrm{OH}^{-}$flux, while the influence of BACs introduction on the $\mathrm{U}_{\mathrm{OH}}$ of the membrane was complicated. When the BACs dosage was $2 \%$, the $\mathrm{U}_{\mathrm{OH}}$ of the membrane was the highest, and the possible transfer mechanism was as follows: When the amount of BACs was low, the formation of the cross-linked structure was imperfect. The ion flux of the membrane mainly depended on ion permeation, and the transport of $\mathrm{OH}^{-}$and $\mathrm{Na}^{+}$mainly obeyed free diffusion [13], so the flux of the membrane was low; when the amount of BACs was $2 \%$, the $\mathrm{U}_{\mathrm{OH}}$ of the membrane was the highest, indicating that the suitable introduction of BACs could simultaneously 
promote ion flux and selectivity. The transport mechanism of $\mathrm{OH}^{-}$and $\mathrm{Na}^{+}$could be concluded as follows: $-\mathrm{COO}^{-}$groups from $\mathrm{BACs}$ formed the main transport channels of $\mathrm{Na}^{+}$via electrostatic attraction; $\mathrm{OH}^{-}$was forced through the membrane via the electroneutrality principle; and thus, $-\mathrm{OH}$ groups in the PVA backbone established an assisted transport channel of $\mathrm{OH}^{-}$through hydrogen bonds [29].

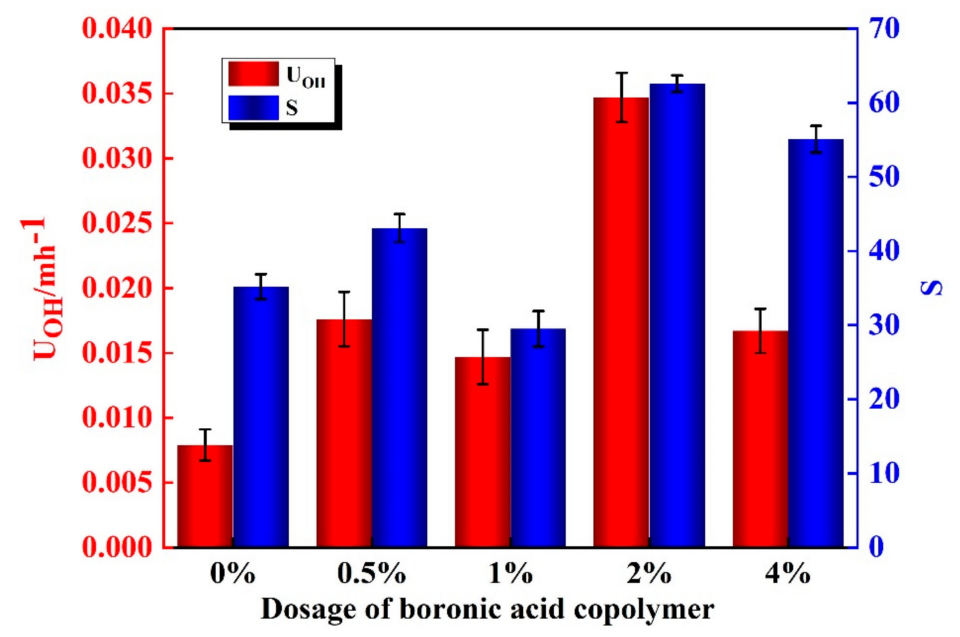

Figure 6. Diffusion dialysis (DD) results of as-prepared membranes.

The proposed mechanism of ions is shown in Figure 7. Both the main transport channels and the assisted channels synergistically promoted the transport of $\mathrm{OH}^{-}$and $\mathrm{Na}^{+}$. Thus, the $\mathrm{U}_{\mathrm{OH}}$ decreased markedly as the dosage of BACs increased to $4 \%$; the cross-linking between $-\mathrm{B}(\mathrm{OH})_{2}$ and PVA increased the density of the membranes, and the number of free-OH groups decreased accordingly as the BACs increased. Therefore, the separation performance of the composite membrane visibly decreased when the dosage of BAC was $4 \%$. In summary, when the amount of BACs was $2 \%$, the composite membrane exhibited optimal separation performance: the $\mathrm{OH}^{-}$dialysis coefficient $\left(\mathrm{U}_{\mathrm{OH}}\right)$ was $0.0347 \mathrm{~m} \mathrm{~h}^{-1}$, and the separation factor (S) was 62.6.

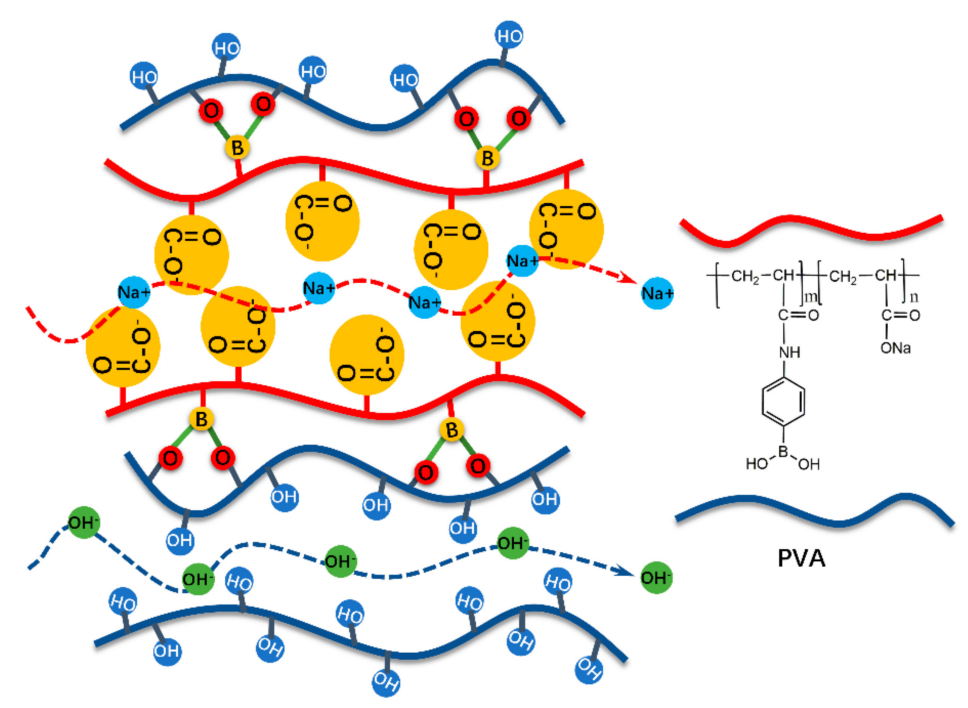

Figure 7. Proposed transport process of $\mathrm{Na}^{+}$and $\mathrm{OH}^{-}$.

To further evaluate the separation performance of membranes in this research, we summarized the related reports and the results are listed in Table 5. The conclusions could be obtained as follows: 
Table 5. Separation performance comparisons $\left(\mathrm{U}_{\mathrm{OH}}\right.$ and $\left.\mathrm{S}\right)$ of membranes in this research and previously reports.

\begin{tabular}{ccccc}
\hline Membrane Matrix & Separation System & $\mathbf{U}_{\mathbf{O H}} / \mathbf{m} \cdot \mathbf{h}^{-\mathbf{1}}\left(\mathbf{2 5}{ }^{\circ} \mathbf{C}\right)$ & $\mathbf{S}\left(\mathbf{2 5}{ }^{\circ} \mathbf{C}\right)$ & Ref. \\
\hline PVA & $0.011-0.022$ & $11.6-20.6$ & {$[26]$} \\
PVA & $0.0079-0.0150$ & $26.6-53.2$ & {$[27]$} \\
PVA & & $0.0065-0.0086$ & $24.4-51.6$ & {$[28]$} \\
SPPO & & $0.0035-0.0061$ & $31.6-37.5$ & {$[29]$} \\
SPPO & & $0.002-0.0038$ & $98-175$ & {$[30]$} \\
PVA & $\mathrm{NaOH} / \mathrm{Na}_{2} \mathrm{WO}_{4}$ & $0.006-0.032$ & $12.2-36.2$ & {$[31]$} \\
PVDF & & $0.0008-0.0061$ & $12.0-90.3$ & {$[32]$} \\
PVA/SPPO & & $0.007-0.013$ & $111-181$ & {$[33]$} \\
CSM & & $0.0018-0.009$ & $9.0-32.3$ & {$[34]$} \\
PVA & & $0.0077-0.0175$ & $21.5-88.8$ & {$[35]$} \\
PVA & & $0.0147-0.0347$ & $29.5-62.6$ & This research \\
\hline
\end{tabular}

(1) Hydrophilic polymer (such as PVA) possessed higher $\mathrm{U}_{\mathrm{OH}}$ than that of hydrophobic ones (such as CSM and PVDF), while ion selectivity was the opposite. The results showed that the natural properties of the polymer matrix had significant effects on the separation performance of the membranes.

(2) Membranes in this research exhibited higher $\mathrm{U}_{\mathrm{OH}}$ and $\mathrm{S}$ than those of the references, which indicated that involvement of BACs could be one of the choices to solve the "tradeoff effects" between ion dialysis coefficients and selectivity in the DD separation process.

\section{Conclusions}

A series of composite membranes were prepared by the blending-casting method, and the separation performance of the as-prepared membranes was evaluated by the recovery of alkali via diffusion dialysis. The as-prepared membranes possessed a moderate $\mathrm{W}_{\mathrm{R}}(122.6-150.0 \%)$, low IECs $\left(0.015-0.052 \mathrm{mmol} \mathrm{g}^{-1}\right)$, and outstanding alkali resistance (swelling degree was in the range of $222.6-241.9 \%$ and mass loss was in the range of $1.9-5.9 \%$ ), which indicated that the composite membranes were suitable for application in alkaline diffusion dialysis processes. All the composite membranes exhibited acceptable mechanical and thermal stability and uniform microscopic morphologies, which confirmed the good compatibility between the PVA and the BACs. The composite membrane possessed optimal separation performance when the dosage of $\mathrm{BAC}$ was $2 \%$, with $\mathrm{U}_{\mathrm{OH}}$ and $\mathrm{S}$ values of $0.0347 \mathrm{~m} \mathrm{~h}^{-1}$ and 62.6 , respectively. Both the $-\mathrm{COO}^{-}$groups from the BACs and $-\mathrm{OH}$ groups from the PVA were considered to play synergistic roles in promoting the transport of $\mathrm{OH}^{-}$and $\mathrm{Na}^{+}$. This work provides a significant idea for further synthesis of anion exchange membranes for alkali recovery applications.

Author Contributions: L.P. and X.H. performed most of the experimental work and data analysis, L.P. wrote the first draft of the manuscript as well. D.L. carried out the experiments and took part in the data analysis and discussion. J.M., B.W., M.C., Q.G., B.Y., L.S. and Z.Z. carried out the review \& editing of manuscript. R.X., P.C. and J.Q. designed and supervised this project and corrected the final draft of the manuscript. All authors have read and agreed to the published version of the manuscript.

Funding: This work was supported by the National Natural Science Foundation of China (Nos. 21606001, 21606215, 51973002, and 21808001), the Anhui Provincial Natural Science Foundation (No. 1708085QE117), the Anhui University Collaborative Innovation Project (No. GXXT-2019-001) and the Doctoral Scientific Research Startup Foundation of Anhui University (No. Y040433005). Particularly, the financial support from the State Key Laboratory of Separation Membranes and Membrane Processes (Tianjin Polytechnic University, No. M2-201706) and the Institute of High-Performance Rubber Materials and Products of Anhui Province were appreciated.

Conflicts of Interest: The authors declare no conflict of interest. 


\section{References}

1. Ignacz, G.; Fan, F.; Szekely, G. Ion-stabilized membranes for demanding environments fabricated from polybenzimidazole and its blends with polymers of intrinsic microporosity. ACS Appl. Nano Mater. 2018, 1, 6349-6356. [CrossRef]

2. Meringolo, C.; Poerio, T.; Fontananova, E.; Mastropietro, T.F.; Nicoletta, F.P.; Filpo, G.D.; Curcio, E.; Profio, G.D. Exploiting Fluoropolymers Immiscibility to Tune Surface Properties and Mass Transfer in Blend Membranes for Membrane Contactor Applications. ACS Appl. Polym. Mater. 2019, 1, 326-334. [CrossRef]

3. Haragirimana, A.; Ingabire, P.B.; Zhu, Y.X.; Lu, Y.; Li, N.; Hu, Z.X.; Chen, S.W. Four-polymer blend proton exchange membranes derived from sulfonated poly(aryl ether sulfone)s with various sulfonation degrees for application in fuel cells. J. Membr. Sci. 2019, 583, 209-219. [CrossRef]

4. Jienkulsawad, P.; Chen, Y.S.; Amornchai, A. Modifying the catalyst layer using polyvinyl alcohol for the performance improvement of proton exchange membrane fuel cells under low humidity operations. Polymers 2020, 12, 1865. [CrossRef] [PubMed]

5. Ates, B.; Koytepe, S.; Ulu, A.; Gurses, C.; Thakur, V.K. Chemistry, structures, and advanced applications of nanocomposites from biorenewable resources. Chem. Rev. 2020, 120, 9304-9362. [CrossRef]

6. McNair, R.; Cseri, L.; Szekely, G.; Dryfe, R.A.W. Asymmetric membrane capacitive deionization using anion-exchange membranes based on quaternized polymer blends. ACS Appl. Polym. Mater. 2020, 2, 2946-2956. [CrossRef]

7. Xu, C.Q.; Xue, S.; Wang, P.; Wu, C.M.; Wu, Y.H. Diffusion dialysis for $\mathrm{NaCl}$ and $\mathrm{NaAc}$ recovery using polyelectrolyte complexes/PVA membranes. Sep. Purif. Technol. 2017, 172, 140-146. [CrossRef]

8. Liu, L.; Xue, S.; Wu, C.M.; Wu, Y.H.; Wang, S. PVA-PSSS membranes for alkali recovery through diffusion dialysis: Effect of alkoxysilanes. Desalin. Water Treat. 2015, 57, 6901-6909. [CrossRef]

9. Xiao, X.; Wu, C.M.; Cui, P.; Luo, J.Y.; Wu, Y.H.; Xu, T.W. Cation exchange hybrid membranes from SPPO and multi-alkoxy silicon copolymer: Preparation, properties and diffusion dialysis performances for sodium hydroxide recovery. J. Membr. Sci. 2011, 379, 112-120. [CrossRef]

10. Wang, H.; Wu, C.M.; Wu, Y.H.; Luo, J.Y.; Xu, T.W. Cation exchange hybrid membranes based on PVA for alkali recovery through diffusion dialysis. J. Membr. Sci. 2011, 376, 233-240. [CrossRef]

11. Luo, J.Y.; Wu, C.M.; Wu, Y.H.; Xu, T.W. Diffusion dialysis of hydrochloride acid at different temperatures using PPO-SiO 2 hybrid anion exchange membranes. J. Membr. Sci. 2010, 347, 240-249. [CrossRef]

12. He, Y.B.; Pan, J.F.; Wu, L.; Ge, L.; Xu, T.W. Facile preparation of 1, 8-diazabicyclo [5.4.0] undec-7-ene based high performance anion exchange membranes for diffusion dialysis applications. J. Membr. Sci. 2015, 49, 145-152. [CrossRef]

13. Luo, J.Y.; Wu, C.M.; Xu, T.W.; Wu, Y.H. Diffusion dialysis-Concept, principle and applications. J. Membr. Sci. 2011, 366, 1-16. [CrossRef]

14. Wang, H.; Xia, Y.; Liu, J.; Ma, Z.; Shi, Q.; Yin, J. Programmable release of 2-O-D-glucopyranosyl-L-ascorbic acid and heparin from PCL-based nanofifiber scaffold for reduction of inflammation and thrombosis. Mater. Today 2020, 100303, 2468-5194.

15. Lin, X.C.; Varcoe, J.R.; Poynton, S.D.; Liang, X.H.; Wu, Y.H.; Xu, T.W. Alkaline polymer electrolytes containing pendant dimethylimidazolium groups for alkaline membrane fuel cells. J. Mater. Chem. 2013, $24,7262$. [CrossRef]

16. Miao, J.B.; Li, X.Y.; Yang, Z.J.; Jiang, C.X.; Qian, J.S.; Xu, T.W. Hybrid membranes from sulphonated poly(2,6-dimethyl-1,4-phenylene oxide) and sulphonated nano silica for alkali recovery. J. Membr. Sci. 2016, 498, 201-207. [CrossRef]

17. Liu, M.H.; Zhou, C.M.; Dong, B.Y.; Wu, Z.F.; Wang, L.Z. Enhancing the permselectivity of thin-film composite poly (vinyl alcohol) (PVA) nanofiltration membrane by incorporating poly (sodium-p-styrene-sulfonate) (PSSNa). J. Membr. Sci. 2014, 463, 173-182. [CrossRef]

18. Dai, C.H.; Mondal, A.N.; Wu, L.; Xu, T.W.; Wu, Y.H. Cross-linked PVA-based hybrid membranes containing di-sulfonic acid groups for alkali recovery. Sep. Purif. Technol. 2017, 184, 1-11. [CrossRef]

19. Wu, C.M.; Gu, J.J.; Wu, Y.H.; Luo, J.Y.; Xu, T.W.; Ping, Z.Y. Carboxylic acid type PVA-based hybrid membranes for alkali recovery using diffusion dialysis. Sep. Purif. Technol. 2012, 92, 21-29. [CrossRef]

20. Shi, F.M.; Ma, Y.X.; Ma, J.; Wang, P.P.; Sun, W.X. Preparation and characterization of PVDF/TiO 2 hybrid membranes with ionic liquid modified nano-TiO 2 particles. J. Membr. Sci. 2013, 427, 259-26921. [CrossRef] 
21. Zhang, J.; Wang, Z.W.; Liu, M.X.; Zhao, F.L.; Wu, Z.C. In-situ, modification of PVDF membrane during phase-inversion process using carbon nanosphere sol as coagulation bath for enhancing anti-fouling ability. J. Membr. Sci. 2017, 526, 272-280. [CrossRef]

22. Xu, Z.W.; Wu, T.F.; Shi, J.; Teng, K.Y.; Wei, W. Photocatalytic antifouling PVDF ultrafiltration membranes based on synergy of graphene oxide and $\mathrm{TiO}_{2}$ for water treatment. J. Membr. Sci. 2016, 520, 281-293. [CrossRef]

23. Pan, Y.; Yu, Z.X.; Shi, H.; Chen, Q.; Ren, X.Q. A novel antifouling and antibacterial surface-functionalized PVDF ultrafiltration membrane via binding $\mathrm{Ag} / \mathrm{SiO}_{2}$ nanocomposites. J. Chem. Technol. Biotechnol. 2016, 92, 562-572. [CrossRef]

24. Chikh, L.; Delhorbe, V.; Fichet, O. (Semi-) Interpenetrating polymer networks as fuel cell membranes. J. Membr. Sci. 2011, 368, 1-17. [CrossRef]

25. Hao, J.W.; Wu, Y.H.; Ran, J.; Wu, B.; Xu, T.W. A simple and green preparation of PVA-based cation exchange hybrid membranes for alkali recovery. J. Membr. Sci. 2012, 433, 10-16. [CrossRef]

26. Liu, D.D.; Wei, W.C.; Miao, J.B.; Ru, X.; Qian, J.S. Composite cationic exchange membranes prepared from polyvinyl alcohol (PVA) and boronic acid copolymers for alkaline diffusion dialysis. Materials 2018, 11, 1354. [CrossRef]

27. Hao, J.W.; Wu, Y.H.; Xu, T.W. Cation exchange hybrid membranes prepared from PVA and multisilicon copolymer for application in alkali recovery. J. Membr. Sci. 2013, 426, 156-162. [CrossRef]

28. Li, X.Y.; Miao, J.B.; Ru, X.; Yang, B.; Qian, J.S. Preparation and properties of sulfonated poly(2,6-dimethyl-1,4-phenyleneoxide)/mesoporous silica hybrid membranes for alkali recovery. Micropor. Mesopor. Mater. 2016, 236, 48-53. [CrossRef]

29. Miao, J.B.; Yao, L.Z.; Yang, Z.J.; Pan, J.F.; Qian, J.S.; Xu, T.W. Sulfonated poly(2,6-dimethyl-1, 4-phenyleneoxide)/nano silica hybrid membranes for alkali recovery via diffusion dialysis. Sep. Purif. Technol. 2015, 141, 307-313. [CrossRef]

30. Hao, J.W.; Gong, M.; Wu, Y.H.; Wu, C.M.; Luo, J.Y.; Xu, T.W. Alkali recovery using PVA/SiO 2 cation exchange membranes with different -COOH content. J. Hazard. Mater. 2013, 245, 348-356. [CrossRef]

31. Lin, X.C.; Shamsaei, E.; Kong, B.; Liu, J.Z.; Hu, Y.X.; Xu, T.W. Porous diffusion dialysis membranes for rapid acid recovery. J. Membr. Sci. 2016, 502, 76-83. [CrossRef]

32. Liu, R.; Wu, L.; Pan, J.F.; Jiang, C.X.; Xu, T.W. Diffusion dialysis membranes with semi-interpenetrating network for alkali recovery. J. Membr. Sci. 2014, 451, 18-23. [CrossRef]

33. Wu, Y.H.; Hao, J.W.; Wu, C.M.; Mao, F.; Xu, T.W. Cation exchange PVA/SPPO/SiO 2 membranes with double organic phases for alkali recovery. J. Membr. Sci. 2012, 442, 383-391. [CrossRef]

34. Chong, F.R.; Wang, C.W.; Miao, J.B.; Xia, R.; Cao, M.; Chen, P.; Yang, B.; Zhou, W.B.; Qian, J.S. Preparation and properties of cation-exchange membranes based on commercial chlorosulfonated polyethylene (CSM) for diffusion dialysis. J. Taiwan Inst. Chem. Eng. 2017, 78, 561-565. [CrossRef]

35. Wang, C.W.; Liang, Y.X.; Miao, J.B.; Wu, B.; Hossain, M.d.M.; Cao, M.; Ge, Q.Q.; Su, L.F.; Zheng, Z.Z.; Yang, B.; et al. Preparation and properties of polyvinyl alcohol (PVA)/mesoporous silica supported phosphotungstic acid (MS-HPW) hybrid membranes for alkali recovery. J. Membr. Sci. 2019, 592, 117-388. [CrossRef]

Publisher's Note: MDPI stays neutral with regard to jurisdictional claims in published maps and institutional affiliations.

(C) 2020 by the authors. Licensee MDPI, Basel, Switzerland. This article is an open access article distributed under the terms and conditions of the Creative Commons Attribution (CC BY) license (http://creativecommons.org/licenses/by/4.0/). 